\title{
Improvement of Precision and its Stability by Using Cooperation Motions and Enhancement of Tribological Property
}

\author{
Xinghui $\mathrm{Li}^{1, \mathrm{a}}$, Huanhuan Wang ${ }^{1, \mathrm{~b}}$, Xiangwen Zhu ${ }^{1, \mathrm{c}}$, Qian Zhou ${ }^{1, \mathrm{~d}}$, Xiang Xiao \\ $1, \mathrm{e}$, and Xiaohao Wang ${ }^{1,2, \mathrm{f}}$ \\ ${ }^{1}$ Graduate School at Shenzhen, Tsinghua University, Shenzhen, 518055, China \\ ${ }^{2}$ The research Institute of Tsinghua University in Shenzhen, Shenzhen, 518057, China \\ ali.xinghui@sz.tsinghua.edu.cn, bhxdhwhh@126.com, 'crczhuxiangwen@foxmail.com,

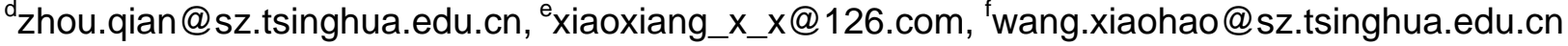

Keywords: Precision; Stability of precision; Cooperation motions; Surface enhancement; Tribology Abstract. In this paper, pursuits of high precision of linear/rotary stages by using cooperation motions and high precision stability via enhancement of the interface of stationary and moving parts are presented. Mechanisms that can provide multi-axis motions with a relative small stroke but a high precision are briefly illustrated. Well-known actuating methods and accuracy available are presented. Tribological properties enhancement of the moving systems for a stable precision is shortly introduced in the last section.

\section{Introduction}

Stages both in terms of the linear one and rotary one are widely employed in production engineering and serve as the basic components of various machines. With increases of requirements on small feature size, compactness, long lifetime of industrial productions, total machining accuracy rapidly increases. Fig.1 summarizes the accuracy values of different machining levels in different ages [1]. It can been seen that, for the ultra-precision processing at present, nm-order accuracy is demanded.

For achievement of such an accuracy, one has to improve the precision of stages. The majority of today's stages are motorized and feedback controlled. System accuracy is comprehensively determined by their actuating principle, sensors technology for position information, and control strategy. So, it is of priority to choose a suitable combination of these three items when one begins to develop stages for industrial application [2]. This research focuses on some ideas to achieve high precision and its stability via introduction of cooperation motions and usage of mechanism with good tribological properties.

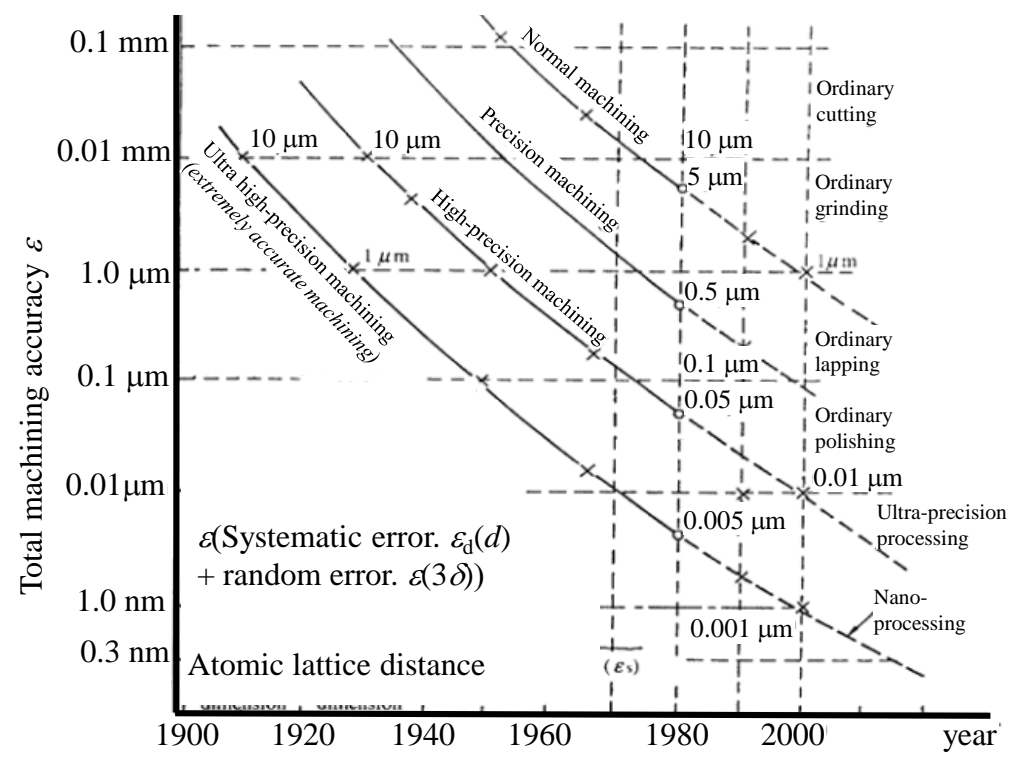

Fig.1 Total machining accuracy standards of different machining levels with ages changing [1] 


\section{Stages and their three key modules}

Fig. 2 schematically illustrates a closed-loop controlled precision stage. The stage is composed of three sections, they are, a mechanism represented by a guideway, a position sensor for feedback control and a controller system represent by a PC and an amplifier. The moving table where a specimen or scanning probe is mounted is moved along the guideway to a reference position $x_{\mathrm{r}}$. The position sensor is set to measure the actual position $x$ of the moving table. The position error, the difference between the reference position and the actual position, is used as a feedback signal for moving table position adjustment. Efforts have to be made to all these three sections when a resolution of better than $0.1 \mu \mathrm{m}$ is desired [2].

Table 1 summarizes the details including main parameters and options of these three sections, they are, design and mechanism, measurement and sensors as well as electronics and control technology, respectively. For a certain accuracy requirement, one can choose different types from this table. It should be noted that not all options, but some typical cases are collected in Table 1.

In the following part of this paper, the design work and mechanism will be emphasized. A cooperation motion design for high precision and improvement of frictional and lubricant property for a good precision stability will be presented. Sensors and control technology are not the scope of this paper and they will be investigated in the future.

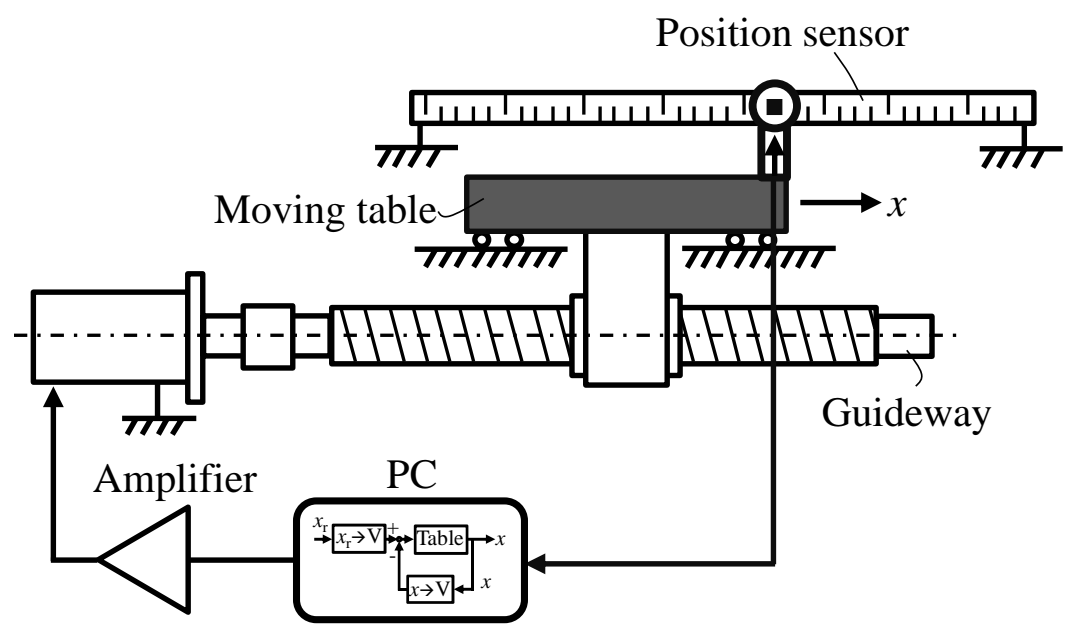

Fig.2 Schematic illstration of a precison stage

Table 1 The main parameters and options of three key items of stages

\begin{tabular}{|c|c|c|}
\hline Item & Main parameters & Options \\
\hline $\begin{array}{l}\text { Design and } \\
\text { mechanism }\end{array}$ & $\begin{array}{l}\text { - Structure properties: } \\
\text { Compactness, Stroke, Weight, } \\
\text { Speed, Accuracy limitation } \\
\text { - Operation properties: } \\
\text { Sustainability, Lifetime, } \\
\text { Environment friendly }\end{array}$ & $\begin{array}{l}\text { - Guiding way: Elastic hinge, Ball or } \\
\text { roller, Sliding bearing, Aerostatic or } \\
\text { electromagnetic bearing } \\
\text { - Driving method: DC-motor, Linear } \\
\text { motor, Piezo }\end{array}$ \\
\hline $\begin{array}{l}\text { Measurement and } \\
\text { sensors }\end{array}$ & $\begin{array}{l}\text { - Single axis: Resolution, } \\
\text { Accuracy, Cost, Robustness } \\
\text { - Cooperation measurement: } \\
\text { Multi-axis capacity, Easy } \\
\text { integration }\end{array}$ & $\begin{array}{l}\text { - Linear motions: Laser interferometer, } \\
\text { Linear encoder, Laser ranger, etc. } \\
\text { - Rotary motions: Rotary encoder, } \\
\text { autocollimator, Tilting meter }\end{array}$ \\
\hline $\begin{array}{l}\text { Electronics and } \\
\text { control technology }\end{array}$ & $\begin{array}{l}\text { - Logic: Real-time, Speed, } \\
\text { Simplicity, Robustness, } \\
\text { Efficiency, Cost, }\end{array}$ & $\begin{array}{l}\text { - } \text { Control: PID, Low-pass, etc. } \\
\text { - Algorithm: HMM, Neural network, etc. } \\
\text { - Hardware: FPGA, ADC, DSP, etc. }\end{array}$ \\
\hline
\end{tabular}




\section{Cooperation motions and coating layer for high precision}

As illustrated in Table 1, mechanism of stages can be divided into two sections, guiding way and driving mechanism. According to the latest catalogs of commercial products of mainstream linear/rotary stage manufactures, accuracy available under different mechanism and different control technology is summarized in Table 2 [3]. It can be seen that an aerostatic bearing supporting and linear motor driven stage can provide the highest precision due to its advantages on non-friction and good controllability. This benefits many applications in the fields of nanoscience and nanotechnology. However, such kind of stages always cost much and the extra air supply system adds complexity.

In fact, in some cases, high precision is not really necessary for the whole motion stroke, for example, some imaging microscopes or lapping machines, the measurement probe or cutting tool is required to be close the sample or workpiece in a high speed, while high precision is only demanded when it measures or cuts. Under such conditions, a better solution is employment of combination motions.

Table 2 Accuracy available under different mechanism and different control technology [3]

\begin{tabular}{|l|c|c|c|c|}
\hline \multicolumn{1}{|c|}{ Speed (mm/s) } & 0.1 & 1 & 10 & 100 \\
\hline Errors $(\mu \mathrm{m})$ & 8 & 7 & 6 & 3 \\
\hline Ball Screw + Roller Guide + PID & 1 & 1.5 & 2 & 0.8 \\
\hline $\begin{array}{l}\text { Ball Screw + Air Bearing + PID } \\
\text { +Off servo }\end{array}$ & 0.4 & 0.6 & 0.9 & 1.2 \\
\hline $\begin{array}{l}\text { Linear Motor+ Roller Guider +PID } \\
\text { Linear Motor+ Roller Guider + PID } \\
+ \text { Off servo }\end{array}$ & 0.2 & 0.65 & 3 & 0.8 \\
\hline $\begin{array}{l}\text { Linear Motor+ Air Bearing + PID } \\
\text { Linear motor+ Air Bearing + PID + } \\
\text { Off servo }\end{array}$ & 0.08 & 0.07 & 0.06 & 0.4 \\
\hline
\end{tabular}

Fig.3 illustrates the schematic of cooperation motions by combination of a fine moving table with a coarse one. The DC-servo motor driven and ball-screw guided stage employs a roller guiding way. This mechanism is initially designed for precision application and it is generally less expensive than that using air bearing supporting one. Thus, it cannot meet many high precision applications. However, if a local actuator with high/ultra-high precision ability was integrated into this mechanism, as shown in this figure, it can offer an equivalent function but not improve the cost much. The local actuator here is not necessary to be large, to provide large stroke, but only a compact, high accuracy, fast response can meet these requirement, such as electromagnetic motor, piezo level stages, etc. as shown in Table 1.

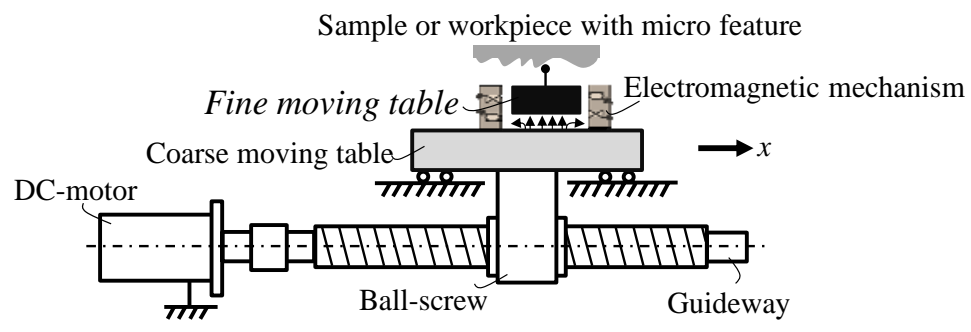

Fig. 3. Cooperation motions by combination of a fine moving table with a coarse one

It should be noted that apart from the precision itself, stability of precision is also signifcant for production engineering, which decides the product quality, the changeablity of products and lifetime 
of the machine tools. Cause the majority of the stages are using a contact type friction moving element, wear and lubrication are main subjects needed to be carefully investigated.

Fig. 4 illustrates the friction model between stationary part and moving element. Lubricant both in terms of grease or oil film is generally used to reduce the wear. And a coating layer is also of priority to be used to enhance the sruface of the stationary part [4]. For reduction of enviromental polution, usage of some kinds of self-lubrication materials is reported [5].Besides of the self-lubrication and conventional grease of oil lubrication, advanced magnetic fluid (MF) is emerging and employed for planar motion table [6]. The MF can serve as lubricant as conventional one, while the micro particles inside can be activated by an outer magnetic flied. The viscosity can be adjust to adapt different tribological conditions. This characteristic is significant for the complicated lubrication requirement.

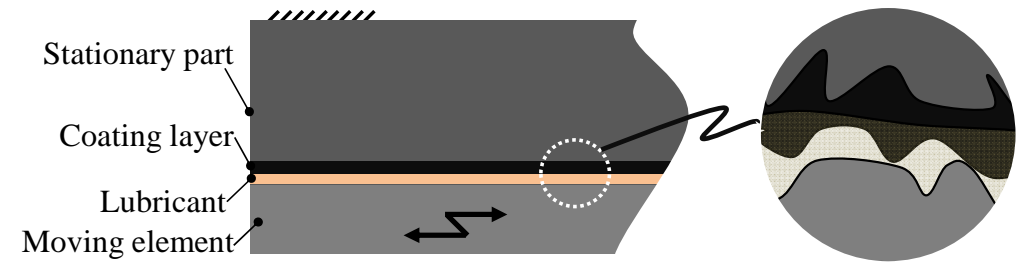

Fig. 4 Frequence response testing result in X-direction

\section{Conclusions and discussions}

Development of proper mechanisms is of the first importance for achievement of high precision of stages. Combination of fine moving table with a coarse one is a valuable idea that can benefit many applications. Selection of suitable coating layer such as self-lubrication material and advanced lubricant for example, magnetic fluid can improve the precision stability.

Besides, construction of a planar type stage by using surface motors [7] and employment of multi-axis encoders [8-11] are also newly developed technology to improve the precision of stage systems.

\section{Acknowledgements}

This work was financially supported by the China Postdoctoral Science Foundation Funded under Projects No. 2016T90089 and No. 2015M571033, the Shenzhen Fundamental Research Program under No. JC201005280634A.

\section{References}

[1] N. Taniguchi: CIRP Ann., 1982, 32(2), p.573.

[2] W. Gao, W. Kim, H. Bosse, H. Haitjema, Y. Chen, X. Lu, W. Knapp, A. Weckenmann, W. T. Estler, and H. Kunzmann: CIRP. Ann 64(2), 2015, p.773.

[3] Y. Tomita, E. Kojima, S. Kawachi, Y. Koyanagawa and S.Otsuku: JSPE J. 78(2), (2012), p.117.

[4] X. Yuan, H. Wang, G. Hou and B. Zha: J. Therm. Spray Technol., 15(3), 2006, p.413.

[5] C. G.Guleryuz, J. E. Krzanowski: Surf. Coat. Technol. 204, 2010, p.2392.

[6] Li X, Shinshi T, Hijikata W, and Morimoto Y, Rev. Sci. Instrum. 87(6). 2016, p. 065003.

[7] W. Gao, S. Dejima, H. Yanai, K. Katakura, and S. Kiyono: Precis. Eng. 28, 2004, p. 329.

[8] Y. Shimizu, T. Ito, X. Li, W. Kim, and W. Gao: Measur.Sci. and Tech., 25(9), 2014, p.094002.

[9] Gao, W., and A. Kimura, CIRP Ann. 56, 2007, p. 529-532.

[10]Li, X., Gao, W., Muto, H., Shimizu, Y., and Ito, S., Precis. Eng., 37(3), 2013, p.771.

[11]Li, X., Shimizu, Y., Ito, T., Cai, Y., Ito, S., and Gao, W., Optical Eng., 53, 2014, p.122405. 